\title{
Is dyslexia real or simply a myth in education context?
}

\author{
Ulan Tlemissov ${ }^{1, *}$, Gulnara Saparova ${ }^{1}$,Ermek Abilmazhinov ${ }^{1}$, Saltanat Karimova ${ }^{1}$, \\ and Zhansaya Tlemissova ${ }^{2}$

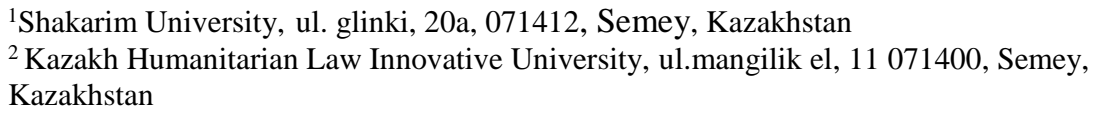

\begin{abstract}
This paper considers a hot debate ensues in attempt to find a satisfactory answer to the question, 'Is dyslexia real or simply a myth? This especially comes after remarks from a prominent member in the modern society, the Labour Backbench MP, Mr. Graham Stringer, who asserted that dyslexia was a myth brought forth by education practitioners as cover up for their poor methods of teaching. To a similar extent, the attempt to equally provide a yielding definition for the term dyslexia has also been vain, according to different researchers, the strings of meaning and concepts attached to the term appear to fit their own descriptions and past experiences. The end result of most consequential arguments and debates leave the matter unresolved, this is despite the fact that dyslexia, a type of disorder to many, is a term that has remained quite relevant in most social contexts in recent times. This paper discusses the various arguments that are put forward by main opponents and proponents to the existence of dyslexia, and concludes that dyslexia is a myth, and it is simply a term used broadly to describe the difficulties or limited abilities in demonstrating literary skills, as identified in different people, especially leaners in education contexts
\end{abstract}

\section{Introduction}

A hot debate ensues in attempt to find a satisfactory answer to the question, 'Is dyslexia real or simply a myth? This especially comes after recent remarks from a prominent member in the modern society, the Labour Backbench MP, Mr. Graham Stringer, who asserted that dyslexia was a myth brought forth by education practitioners as cover up for their poor methods of teaching [1]. To a similar extent, the attempt to equally provide a yielding definition for the term dyslexia has also been vain, according to different researchers, the strings of meaning and concepts attached to the term appear to fit their own descriptions and past experiences. The end result of most consequential arguments and debates leave the matter unresolved, this is despite the fact that dyslexia, a type of disorder to many, is a term that has remained quite relevant in most social contexts in recent times. This paper discusses

\footnotetext{
* Corresponding author: ulangov@mail.ru
} 
the various arguments that are put forward by main opponents and proponents to the existence of dyslexia, and concludes that dyslexia is a myth, and it is simply a term used broadly to describe the difficulties or limited abilities in demonstrating literary skills, as identified in different people, especially learners in education contexts.

\section{The Concept of Dyslexia}

According to the British Dyslexia Association (BDA), dyslexia is a term used to describe a particular learning difficulty that is exhibited by diminished language and literary skills. Persons who are regarded as dyslexic exhibit the difficulties in their life-long development [2]. This description of the term dyslexia implies that the difficulties in acquisition and demonstration of literary skills is innate, and as such, a distinction between poor literary skills that are attributed to poor teaching methods and those that are influenced by dyslexia should be easy to draw. This however, fails to be the case replicated in the various learning contexts in which the difficulties in learning language and literary skills are seen to have a definite cause, and are thus reversible. For instance, the various symptoms of dyslexia as identified by the BDA (2007), including difficulties in; rapid naming, phonological processing, processing speed, and working memory, may not always be present among persons labeled as dyslexic, and yet having an above average Intelligence Quotient (IQ), see figure 1.

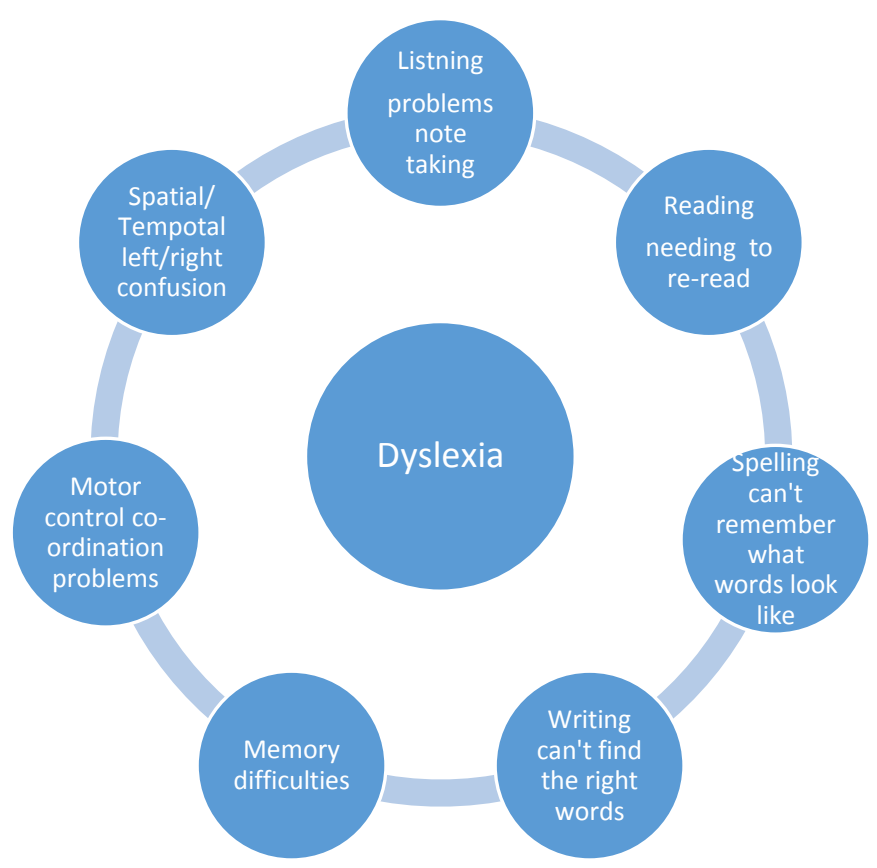

Fig.1. The Concept of Dyslexia (made by authors).

The examples given above are among the most common symptoms used to describe dyslexia. If related to the assertions by Graham Stringer, use of the term dyslexia appears to be of little relevance, especially while providing a correct description of what contributes to the poor language and literary skills exhibited by the over 35,000 students (UK), who according to the current government statistics receive disability funding and allowances amounting to $£ 78.4$ million annually [1]. In light of the MP's argument, the assertions are based on the fact that, each individual student among the 35,000 labelled as dyslexic, exhibits symptoms that vary 
or provide no close resemblance to those exhibited by the others. In addition, the figure in itself raises questions of certainty, and the extent to which the learning difficulties exhibited by those students are attributable to dyslexia. In addition, the scenario painted by the proportions of the dyslexic population in places like West Dunbartonshire, does not seem to relate to that in countries like South Korea or Nicaragua, which according to MP Graham Stringer, have literary rates that are almost hitting $100 \%$ [1].

\section{Research and Questions Raised Regarding the Reality of Dyslexia}

According to research findings concerning psychological and neurological disorders, the symptoms exhibited by most patients who suffer from disorders like memory loss, dementia and paranoia, are often related and distinct. As such, patients diagnosed with such conditions are easily distinguished. This scenario makes it easy to identify the particular disorders and therefore prescribe effective treatment interventions [1]. Also, physicians are able identify the relatively resistant psychological and neurological disorders that are difficult to treat, and for each, identify the corresponding challenges that make them complex [3]. However, unlike those disorders, dyslexia according to proponents of its existence, does not happen to possess clearly defined conditions or symptoms, and neither can it be said to have under its bracket, a finite range of causes that affect the development of language and literary skills among students. It is therefore fair to conclude that, the causes behind the over 35,000 student's poor literary skills are varied, since they all have different descriptions about their conditions, and that the term dyslexia could have primarily been used as cover up for the failure to identify lasting solutions to the low rates of literary skills in the places affected [1]. Similar to MP Graham's remarks, education officials may also find it easier to mask their inability to improve literacy skills in areas under their jurisdiction, using 'non-existent' psychological or neurological dogma, and instead use the term to mince the millions that are allocated for specialized training or education for the affected students.

\section{Arguments that Discredit the Existence of Dyslexia}

Julian Elliot, like many other educational psychologists, fails to acknowledge the existence of dyslexia [3]. He however leaves an exception to a few cases among a minority of those labelled as dyslexic in the society. Recent studies and research by different and prominent academicians and scientists, have prompted inquiry into the ethicality in using the term dyslexia to label the difficulties observed among students with poor language and literary skills in education institutions, at home, and in the various but general learning contexts. According to the findings of most of these researchers, including Julian Elliot's, there does not seem to exist any substantial and significant evidence to provide proof for the existence of dyslexia, as a certain neurological or psychological disorder, that can suitably be used to explain the poor literacy skills among certain individuals, despite having been previously exposed to conventional teaching and learning [3]. This assertions have often been denied a warm reception among a few members of the society who claim to be victims of dyslexia, or to have experienced difficulties in the acquisition of language and literary skills through conventional education systems. Nevertheless, the arguments presented by opponents appears to sufficiently justify their skepticism.

According to Professor Julian Elliot (2015) and other scholars from Durham and Yale university, dyslexia is a myth, and it is often used as a consolation for students who exhibit poor literary skills simply because they are poor readers, or are simply the unfortunate products of poor education systems that are crippled by poor teaching methods, or the nonattendance to the learning needs of students under such systems [3, 4]. This arguments are likely to be reasonably fetched since almost all students or persons who claim to be dyslexic 
allude to symptoms like; difficulties in reading, writing, pronouncing, and memorizing words. It is often the objective of most education systems to equip leaners with skills and the ability to overcome such difficulties. However, the extent to which different education systems achieve literacy rates depends on key aspects like; the society's commitment to support education, the teaching and learning methods adopted by those education systems, and most importantly, their flexibility in as far as meeting the needs of learners is concerned $[5,6]$. To the less efficient education systems that fail to maintain desirable literacy skills, labels that allude to certain psychological or neurological conditions appear to be a perfect fit, and are therefore used to conveniently cover up for a system's inadequacy [7]. This is mainly because the term dyslexia brings along a 'special' connotation, which provides a favorable scape goat and at the same time preserves the perception that the subjects are still individuals with a high IQ [8].

To Julian Elliot, there is no difference between children who are poor readers and those labelled as dyslexic. He further asserts that the term dyslexia is just a fancy word used by parents whose children have poor literary skills, and also as a way to lay more emphasis on their children's IQ. The argument made by the educational psychologist is not farfetched. This may be seen in the various ways dyslexic students are attended to in comparison to the others, whereby, those labelled as dyslexic are accorded specialist care and learning, and in most cases, varied IQ test that are used to demonstrate that such students have normal capabilities and aptitude in other areas of life apart from those that involve language and literary skills [3]. However, the fact that dyslexia is not attributed to certain biological conditions that limit the dyslexics from showing normal literary abilities, and the few that are cited by persons with the conditions are not verifiable using any empirical means despite them having normal IQ, implies that students with poor literary skills resulting from poor methods of teaching provided by education systems, may equally be labelled as dyslexics [9]. In addition, Julian also sees dyslexia as being entirely an English problem since most cases regarding the disorder appear to dominate Britain and other English speaking countries, this is because most literacy difficulties associated with dyslexia have been observed more among students whose education systems involves encounter with English phonetics, which is as compared to other language speaking countries like the Chinese and Arabs [10]. Furthermore, phonetics in the English language is seen to possess a lot of complexities, for instance, words like cinema and cut begin with a common alphabet and yet are pronounced differently.

Another issue that creates a greater urge to raise query on the existence of dyslexia, or provide more proof to ascribe meaningfulness to the term dyslexia in describing the difficulties dyslexics face in reading, writing and language, is the large number of students who are currently given the label, and are apparently subjects to governmental funding and allowances similar to those allocated to persons with special needs. According to MP Graham Stringer, the figure was at 35,500 and growing [1]. The fact that each student among the 35,500 claims to be dyslexic and yet portrays different symptoms from the others, means that a clear and verifiable basis with which the student's poor literary skills could be categorized under, does not exist, and therefore, it is fair to conclude that dyslexia is simply a cover up story, which is used by the parents and teachers of such students in concealing the fact that their students are struggling with reading, writing and language [11]. The assertions by the labour MP are thus meant to act as a wakeup call for the wider society and particularly to the government, since apparently, huge amounts of money are being allocated to offer specialized care and support to students with a disorder that seemingly does not exist.

Most academicians and educational psychologists agree that different teaching and learning methods appeal to different learners with diverse learning needs. This is a likely suggestion that; every individual among the over 35,000 students labeled as dyslexic could respond positively if the suitable teaching methods are used to cater for their learning 
requirements [3]. If this is as such, then claims that all the students are dyslexic are false, which is simply because each of the student has different conditions from the others. If dyslexia as a condition that is exhibited by difficulties in the acquisition of language and literary skills really existed, then a particular method of intervention could produce similar results if used to treat the condition in each of the students [12]. A good example is the current scenario in West Dunbartonshire, where the false disorder has been completely eradicated using specialized methods of intervention [1]. The high proportions of dyslexic persons in Britain exist simply because the education systems and officials have not adopted the correct teaching methodologies. For instance, the current situation in countries like South Korea and West Dunbartonshire is a strong indication that dyslexia is simply a myth, and the low literacy rates in Britain do not result from innate conditions that are hard to fix [2]. According to MP Graham Stringer's remarks and those of Julian Elliot, the use of linguistic phonics could end that falsehood that reigns when the society blindly acknowledges the existence of dyslexia.

Another issue that raises query into the ethicality of dyslexia, as a label for students with difficulties in acquisition and expression of literary skills, is the notion that dyslexics either exhibit writing and reading difficulties or both. This makes it very difficult to distinguish between persons who have poor literary skills due to lack of exposure to quality learning, and those whose poor literary skills are as a result of innate and inhibitive conditions. Proponents of the existence of dyslexia usually quote IQ levels while attempting to distinguish between the two types of persons [13]. For instance, they are quick to label students with poor literary skills but having normal or above average IQ as dyslexics, and thus prescribe specialized training and modified conditions for examinations for such students. Similar to the MP's remarks, such an undertaking is 'wicked', since it accords specialized training and care to the students with normal and above average IQ, and leaves those with a low IQ to languish in illiteracy [11]. Using the level of IQ to diagnose dyslexia is therefore false because students regardless of the levels of their IQ, if exposed to poor teaching and learning methodologies, would conveniently demonstrate poor literary skills in tests.

According to Julian Elliot and other researchers from York University, there exists substantial evidence that children of both high and low IQ levels can be helped to improve their literary skills [3]. As such, there is no need to label one group as dyslexic simply to command special care and attention. To help both groups acquire and demonstrate progressive improvement in literary skills, the researchers recommend that the correct reading and writing programs be developed and implemented in the appropriate way [14]. It is therefore unjust to deny one group special attention and resources at the expense of the other. Acknowledging the existence of dyslexia is therefore synonymous to the approval of inhumane and unjustified means in resource distribution in education systems [11]. This is because dyslexics are usually given extra care and attention that is more resource intensive, and this could otherwise be avoided if the right reading and writing programs are availed to them. According to an article by Joanna Moorhead [15] published on the guardian and entitled 'Is dyslexia just a myth', the author asserts that; the wide range of evidence collected from academicians interviewed during the dispatch program indicates that early intervention could a be a possible solution to the difficulties that encompass 'dyslexia' [15].

To further clarify on the matter mentioned above, Joanna cites the results from a certain program undertaken in Cumbria, in which students who had been previously labeled as dyslexic demonstrated tremendous improvements in their ability to read and write [3]. During the implementation of the identified program, students labeled as dyslexics were immersed in a twelve-week intensive course that was focused on improving their literary skills. According to Joanna, the program was a success since it rose the children's reading age by eight to nine months. The findings from the Cumbria program could further be used as evidence to discredit dyslexia, and justify all attempts to label the 'malady' as a myth. This 
is because, unlike the Cumbrian program, conventional programs adopted for dyslexics are life-long and embedded throughout the entire education system. What makes this even worse is the fact that the progress and improvement of literary skills among learners is often very slow and at times hard to identify. For instance, the programs for dyslexics in both primary and secondary school levels involve very expensive resource inputs and interventions. Also, such privileges are often denied to students with poor literary skills simply because they have a below average IQ level [11]. This begs for the question, "why is the progress and improvement process among the dyslexics with high IQ slower than that recorded among the diverse students under the Cumbrian program identified by Joanna?' Since researchers have identified evidence to the possibility of improving language and literary skills among poor readers or among those who experience writing difficulties, and that also indicates the possibility of achieving the improvements within time frames that are significantly shorter that those prescribed under dyslexia programs, then why proceed with the dyslexia program? Why label children with poor language and literary skills dyslexic, and yet their conditions can be improved through intensive training and specialized programs that are not as resource intensive? [14].

Another issue that further compels us to insinuate the non-existence of dyslexia, is the absence of uniform tests and clear guidelines or a basis with which dyslexics are identified. Different psychologists also appear to rely on different methods for testing the disorder [3]. According to Julian Elliot, most psychologists rely on their own ideologies while trying to ascertain whether dyslexia exists among persons. For instance, certain psychologists will assess a person's ability to memorize words, sounds, or even the ability to process visual signs and symbols. This implies that psychologists have failed to reach an agreement on what conditions actually constitute dyslexia [16]. Since this is the case, then dyslexia could simply be a reference term on which all reading, memory, and writing problems are tagged [11]. It is therefore easy to conclude that the high magnitude term is insignificant, and that the term is simply used as a cover up by education officials who run poor education systems, and parents who can't stand to acknowledge the fact that their children are poor readers or slow learners. In addition, the fact that psychologists have terribly failed in identifying the set of conditions or problems that encompass dyslexia among dyslexics, implies that no meaningful tests are performed to justify its existence among the thousands of children placed under dyslexia programs in Britain [1]. In the light of Julian Elliot's remarks, it is therefore easy to see that proponents of dyslexia are proponents of myth and upholders of falsehood, since one and only one of the following conditions is true, that is, all persons with writing and reading problems qualify to be labeled as dyslexics, or that all of them fail to qualify for the term. This is because each poor reader attributes his condition to the existence of certain inhibitive conditions, or previous experiences that left them unequipped with literary skills, and of all those conditions, none qualifies as a key indicator for the existence of dyslexia among patients who visit psychologists hoping that they are diagnosed with dyslexia, and not told straight to the face that their skills are poor due to exposure to poor methods of teaching and learning in school $[14,18]$. The absence of a set of tests or basis for testing dyslexia therefore implies that dyslexia does not exist, and if it does, then it qualifies as a label that is used by a few to achieve certain vested interests or mask the shame of living with a diminished ability to demonstrate normal language and literacy skills.

\section{Arguments that point to the possible existence of dyslexia}

Analyzing the arguments provided above gives a strong conviction that dyslexia does not exist, and that use of the term is based on misconceptions that are apparently a plaque to education systems. However, proponents of dyslexia's existence are still reluctant to yield to findings from current research, among them are particular psychologists, parents and students 
who strongly claim to have experienced the disorder or witnessed its grip on victims who are usually close relatives or persons under their care [3]. It is therefore ethical and equally fair to delve into the wide range of arguments presented by the proponents, this is equally important since it would help to establish the certainty of both claims from proponents and opponents, which is in as far as the question regarding the existence of dyslexia is concerned. In addition, looking into the arguments would help affirm the conclusions that will be made after this discussion. Apparently, there are as many persons who discredit the existence of dyslexia, as there are those who credit its existence [17]. Among the major proponents include psychologists who claim to have diagnosed the condition in a number of their patients, and students who have grown accustomed to the term as a label for their conditions and difficulties in the acquisition and demonstration of language and literally skills. This also includes the parents of such students.

According to an article presented by Annie Murphy to the editor of the opinion column on the New York Times on February 12 $2^{\text {th }}$ 2012, and entitled, "The Upside of Dyslexia", millions of 'dyslexic' persons are struggling with the condition, and that reading and writing problems or difficulties could surpass beyond the normal, and in which case, such difficulties could not be attributed to negligence of teachers or exposure to poor education systems [19]. The author asserts that the fact that dyslexic programs are normally recommended for students with a high IQ, or for those who possess unique strengths, is the likely reason behind the few attempts to research on the extent to which dyslexia affects the lives of its subjects negatively. Annie Murphy further asserts that dyslexia is real, and as a learning disorder, students who suffer from the condition are greatly affected in a far as learning of language and literary skills is concerned [11]. However, she fails to provide substantial evidence to prove that the condition is real, which could otherwise help in raising the awareness about the disorder. Like Annie Murphy, most proponents allude to proofs that are abstract, in other words, they fail to provide concrete evidences that are verifiable through empirical means.

In the article, The Upside of Dyslexia, Annie, the author describes dyslexia as an emotion loaded term, which is mainly used to label children with learning difficulties that have proved resistant in the course of time, or for those children with different problems that contribute to their poor literary skills [19]. However, the author contends that these problems or difficulties are common among dyslexics and poor readers, and as such, he fails to see the basis with which dyslexics could be distinguished from normal persons with literary problems. In an attempt to provide a lasting solution to the debate on whether dyslexia is real or simply a myth, Joanna looks into the various definitions of dyslexia as put forward by various psychologists, education psychologists, and organizations that dedicate their work to assisting dyslexics [17]. The author acknowledges that there still remains a great deal of confusion regarding what dyslexia typically entails. It seems according to him that; the term dyslexia applies suitably to any individual with literacy problems. Furthermore, Joanna asserts that his research on the matter has raised his awareness about the possible existence of two distinct typologies of dyslexia, that is, acquired dyslexia and developmental dyslexia.

According to Joanna [15], acquired dyslexia is a disorder that results from a brain trauma or any physical damage to the parts of the brain that are responsible for the acquisition and demonstration of literary skills. He further asserts that, acquired dyslexia could occur at any developmental stage of persons, and therefore affect the person's literacy that had been previously acquired. This implies, any sudden loss of literacy skills by individuals who had high literacy skills initially could be explained by Julian's theory. In addition, Joanna suggests that the level of acquired dyslexia is directly proportional to the amount of damage and the areas of the brain that are damaged. He sees this as a possible explanation to the varied literacy levels among different students who have a history of normal or above average literacy, but happen to have suddenly lost the ability to demonstrate their language and literacy skills. Joanna relates victims of acquired dyslexia to those of stroke, whereby, he 
likens the process by which stroke victims lose literacy skills to the process by which victims of dyslexia lose their literacy skills. The arguments presented by Joanna are valid and significant in as far as explaining loss of literacy among persons who have suffered a brain trauma [17]. The logic behind this argument is that; if that particular part of the brain responsible for learning literacy skills s damaged, then it follows that the corresponding literacy skills are also lost or affected to a similar extent.

However factual Julian's arguments regarding acquired dyslexia may be, he still fails to provide proof or evidence regarding the existence of dyslexia. In addition, acquired dyslexia appears to be a very complex term to label persons with poor literary skills owing to a brain damage. In other words, brain trauma or damage does not in itself qualify to be labeled as a disorder; rather, it simply qualifies as a justifiable explanation for the poor literacy skills observed among victims of brain trauma [20]. The fact that a brain trauma could slightly affect ones literacy skills or wipe out the entirety of literacy skills acquired previously, maybe used to explain the different problems and difficulties that results to literacy skills among victims of brain injury. However, this does not permit them to specialized training under dyslexic programs [17]. Depending on the severity of the injury, the trauma could be treated through biological procedures, which would leave little room for psychotherapy since any brain damage does not to a malady, rather, a malady may be a likely result of brain damage. It is therefore false to acknowledge that a complex brain disorder that is termed as 'dyslexia' exists and whose actual problem is brain damage.

Developmental dyslexia according to Joanna [15], refers to certain neurological deficits that contribute to poor literacy skills, or that result to difficulties in acquisition and demonstration of language and literacy skills among persons, and especially among students. Joanna further asserts that developmental dyslexia could occur in two folds, as a result of an individual's genetic makeup which exhibits the neurological deficit, or as a result of some neurological damage of a fetus' brain during gestation [16]. According to David, the neurological deficit or damage affects the areas of the brain responsible for learning literacy skills among dyslexics. This implies that; unlike acquired dyslexia, developmental dyslexia is innate and impairs any attempts by the victims to learn literacy skills. Like most opponents however, Joanna also fails to acknowledge the ethicality of dyslexia or even its existence. This is because acquired and developmental types of dyslexia as he describes, are only limited to a few proportion of the entire group of persons who are labeled as dyslexic. This implies that there are loads of cases and instances in which the learning difficulties among dyslexics cannot be explained in terms of brain damage or neurological deficiencies. For instance, there are cases where students who initially demonstrated normal or above average literacy skills, end up losing their ability to demonstrate the same skills as they develop, and in such cases, no perceivable damage to the brain is evident [21]. Such cases therefore create the urge for the inclusion of another subtype of dyslexia. If this is as such, then every difficulty in learning literacy skills among dyslexics commands a unique subtype of dyslexia for a label, which in the long run, deems the term dyslexia meaningless.

Arguments presented by most proponents appear to suit or fit certain victims of reading and writing difficulty. While some allude to genetic disorders, some refer to certain occurrences that left their brain damaged. This fact makes it even more difficult to categorize dyslexia into subtypes, test for its existence, or even list down certain key conditions that constitute dyslexia. The emotional attachment from victims of 'dyslexia' and that of their close relatives to the debate on whether dyslexia exists compels one to delve into research $[3,22]$. This is because; most of them demonstrate high levels of conviction that are however difficult to investigate through scientific means and procedure. Furthermore, each claims that their situation is realer that that experienced by other victims of 'dyslexia'. Since conclusions are often made from hard and concrete evidence, psychologists continue to provide nonsatisfactory explanations and descriptions of the conditions that actually constitute dyslexia. 
This may be the main reason why there is an increasing number of scholars emerging to discredit the existence of dyslexia [2]. However, for victims whose conditions remain resistant to conventional methods of intervention, 'dyslexia' appears to be the most suitable term to label their condition, after all, there are dozens of varied meaning attached to the term.

\section{Conclusion}

Many researchers among them psychologists, education psychologists, and academicians, continue to research on dyslexia, mainly in an effort to clearly identify the conditions that constitute dyslexia among students with difficulties in reading and writing. Despite the fact that huge amounts of capital and resources have been dedicated in a similar attempt, researchers have not been able to produce concrete evidence that proves dyslexia exists. While countries like Britain continue to channel millions on specialized training for dyslexics, skepticism and criticism in different cultural contexts continues to grow [20]. An example of such an incident may be seen by the remarks by the Labour MP, Mr. Graham Stringer, who labels dyslexia as a myth, and further asserts that the term is used by education officials as cover up for the poor teaching methods that are thriving in education systems that are under their jurisdiction. To Julian Elliot, an education psychologist, dyslexia is used by most parents who have dyslexic students, to mask the fact that their children are "poor readers' and 'poor writers' in equal measure. Analyzing findings from available research provides information that supports the sentiments of the labor MP, and the arguments presented by Julian Elliot [3]. For instance, findings from current research indicate that: psychologists have been unable to provide proof for the existence of dyslexia; conditions that constitute dyslexia still remain unidentified; and that psychologists have also failed to agree on a common procedure for testing dyslexia among students. It is therefore fair to conclude that dyslexia as a learning disorder does not exist, and this is simply because the conditions that constitute it are inexistent, and also because the learning difficulties among dyslexics in the acquisition of literacy skills are too diverse to be categorized as symptoms of a single disorder. Similar to Julian's and the MP's remarks, if dyslexia really existed, countries like South Korea could not be able to achieve literacy rates close to $100 \%$, while over 35,000 students in Britain continue to exhibit poor literacy skills despite the fact that both countries lay an equal importance of education [2]. In addition, there exist specialized programs that could be used to improve literacy among 'dyslexics' within a significantly short period of time as observed in West Dunbartonshire [23]. This implies that education systems that acknowledge the existence of dyslexia are a failure in the society, which is simply because they have failed to meet the needs of their learners by for instance adopting special programs for students with poor reading and writing skills like those recommended by researchers from York and Yale University [3]. The teachers have a great opportunity to learn from their leaders as the latter have the capability to direct the hard working teachers in a better direction so that their talents could be effectively exploited for the betterment of the school. [24,25,26] Dyslexia is therefore a myth, or a term that is used as a quick label for students who have undergone education systems that are not effective, or by parents who do not wish to acknowledge the fact that their children are poor readers or have writing skills, and yet their reading and writing difficulties are a reality to them.

\section{References}

1. BBC News, MP Brands Dyslexia a fiction (2009)

2. A. Furnham, Psychology, 4, 940 (2013) 
3. J. Elliott, \& W. Resing, Journal of Intelligence, 3, 137-157 (2015)

4. Z. Sayabek, M. Arzayeva, M. Gulbazar, A. Mustafina, \& T. Ulan, IBIMA 2017 - Vision 2020, 4152-4160 (2017)

5. S. Bell, \& B. McLean, Special Educational Needs: A Guide for Inclusive Practice, 152 (2016).

6. G. Dauliyeva, G. Supugaliyeva, M.Daribayeva, K. Bizhanova, \& U. Tlemissov, IBIMA 2018 - Vision 2020: Sustainable Economic Development and Application of Innovation Management from Regional Expansion to Global Growth, 6221-6230 (2018)

7. S. Gibbs, Dyslexia, 20, 1-18 (2014)

8. J. Elliott, \& S. Gibbs, Journal of Philosophy of Education, 42, 475-491 (2008)

9. J. Elliott, \& E. Grigorenko, Cambridge University Press (2014)

10. C. Hunt, Beyond Early Writing: Teaching Writing in Primary Schools (2015)

11. F. Romberg, B. Shaywitz, \& S. Shaywitz, AMA Journal of Ethics, 18, 975. (2016)

12. Robertson, C., Angela McLachlan, University of Manchester, UK, 341 (2014)

13. Pavey, B. E. Dyslexia and Early Childhood: An Essential Guide to Theory and Practice. Routledge (2016)

14. Joanna,M., Retrieve from (2005)

15. Cameron, H., \& Billington, T. Studies in Higher Education, 1-15 (2015)

16. Jenkins, J. H., The Psychologist, 18, 729 (2005)

17. Yermentqyeva, A. R., Nurtaev, E., Oralkanova, I. A., \& Moshkalov, A. K., Middle East Journal of Scientific Research, 14, 480-484. (2013)

18. New York Times, Retrieved from http://www.nytimes.com/2012/02/13/opinion/thereality-of-dyslexia-millions-struggle.html (Feb 12, 2012)

19. Elliott, J. G., \& Grigorenko, E. L., The dyslexia debate (No. 14). Cambridge University Press. (2014)

20. Büttner, G., \& Hasselhorn, M., International Journal of Disability, Development and Education, 58, 75-87 (2011)

21. Snowling, M. J., Dyslexia . Blackwell publishing (2000)

22. Peer, L., \& Reid, G. (Eds.)., Special Educational Needs: a guide for inclusive practice. Sage (2016)

23. Ziyadin, S., Shash, N., Kenzhebekova, D., Yessenova, G., \& Tlemissov, U., Data in Brief, 18, 1127-1133 (2018)

24. Sayabek, Z., Madiyarova, A., Ulan, T., Gulvira, A., Aizhan, K., \& Zhanar, T., Academy of Strategic Management Journal, 17, 1-13 (2018)

25. Akhmetshin, E. M., Romanov, P. Y., Zakieva, R. R., Zhminko, A. E., Aleshko, R. A., \& Makarov, A. L. Journal of Entrepreneurship Education, 22 (2019). 